\title{
Vivencia de palabras, significado secundario y poesía. Sobre la idea de un lenguaje propiamente humano en Wittgenstein ${ }^{*}$
}

\section{Experiencing words, secondary meaning and poetry. About the idea of a properly human language in Wittgenstein}

\author{
Eduardo Fermandois \\ Pontificia Universidad Católica de Chile \\ eferman02@yahoo.de
}

Resumen • Entre los años 1946 y 1949, concluida ya la larga elaboración de la primera parte de sus Investigaciones filosóficas (1929-1945), Wittgenstein vuelve a menudo sobre temas relacionados con dos nociones que él mismo acuña: «vivencia de palabras» (Worterlebnis) y «significado secundario» (sekundäre Bedeutung). Los objetivos del presente artículo son los siguientes: exponer, distinguir y relacionar las expresiones «vivencia de palabras» (o también «vivencia del significado») y «significado secundario» (secciones 2,3 y 4); cuestionar una interpretación predominante, según la cual la llamada «ceguera para el significado» (Bedeutungsblindheit) se reduce a la incapacidad de percibir sutilezas del lenguaje poético, a fin de sugerir que nuestro autor apunta más bien a la idea de un lenguaje propiamente humano (secciones 5 y 6); esclarecer la relación entre significado secundario y metáfora (sección 7); y mostrar qué puede querer decir todo lo anterior con relación al juego de lenguaje poético (sección 8).

Palabras clave: vivencia de palabras, significado secundario, ceguera para el significado, lenguaje humano, lengua materna, poesía.

\begin{abstract}
Between 1946 and 1949, having concluded his long-term work on the first part of Philosophical Investigations (1929-1945), Wittgenstein repeatedly comes to deal with topics related to two notions he coined as «experience of a word» (Worterlebnis) and «secondary meaning» (sekundäre Bedeutung). The present article has the following objectives: to expose, distinguish and interrelate the expressions «experience of a word» (or «experience of meaning») and «secondary meaning» (sections 2, 3 and 4); to question a dominant interpretation according to which the so called «meaning-blindness» (Bedeutungsblindheit) amounts to the incapacity to perceive the subtleties of poetic language and to suggest alternatively that the author is pointing to the idea of a specifically human language (sections 5 and 6); to clarify the relation between secondary meaning and metaphor (section 7); and to explain what can all this mean with respect to poetry as a language game (section 8).
\end{abstract}

Keywords: experiencing (the meaning of) a word; secondary meaning (or secondary sense), meaning-blindness, human language, mother tongue, poetry.

* Este trabajo ha sido realizado en el marco del Proyecto Fondecyt Regular N 1080654: «Lo humano, la verdad y la filosofía en el tercer Wittgenstein». Por el correspondiente apoyo económico, agradecemos expresamente a la Comisión Nacional de Investigación Científica y Tecnológica (Conicyt). 
La idea del espíritu humano, que se ve o no se ve, es muy parecida a la idea del significado de una palabra, que se sitúa junto a la palabra, como proceso o como objeto.

Wittgenstein, Últimos escritos sobre filosofía de la psicología ${ }^{1}$

Amo tanto a las palabras.

Neruda, Confieso que he vivido

\section{EXPLÍCITO E IMPLÍCITO}

Acaso uno de los modos más productivos de leer a un filósofo imprescindible sea combinando las ideas que sus textos plasman de un modo explícito con aquellas que sólo aparecen - si es que aparecen-implícitamente. En efecto, la estrategia de incluir cuestiones meramente implícitas en textos filosóficos de envergadura para ensamblarlas con otras formuladas expresamente representa una forma concreta, además de fascinante, de habérselas con dos legítimas pretensiones que nunca debieran percibirse en mutua competencia: de un lado, el empeño hermenéutico por desentrañar en detalle textos de autores que han logrado remozar el tratamiento de asuntos filosóficos y, del otro, el interés sistemático —o mejor, temático- de averiguar sin más cómo son las cosas, es decir, de llegar a planteamientos sobre esos mismos asuntos que lisa y llanamente nos convenzan: más allá o más acá, con desatención o hasta en oposición, a lo desarrollado por el autor que sea.

Entre aproximadamente 1946 y 1949, Ludwig Wittgenstein —uno de esos imprescindibles- volvió repetidas veces sobre temas relacionados con lo que él llama «vivencia del significado» (Bedeutungserlebnis) y "significado secundario» (sekundäre Bedeutung), temas a los que no había prestado atención durante los dieciséis años de trabajo que se condensan en sus Investigaciones Filosóficas (1929-1945)². Los correspondientes textos del hoy por hoy llamado «tercer Wittgenstein» conforman la materia prima del presente trabajo ${ }^{3}$. En su análisis quisiéramos ensayar el difícil pero necesario equilibrio entre la interpretación de textos y la simple reflexión temática, ateniéndonos para ello a la combinación metodológica de lo explícito con lo implícito. Nos centraremos, sobre todo

$\overline{1}$ Letzte Schriften, I 979. Por regla general citaremos de las traducciones al castellano ya publicadas, indicando expresamente aquellas veces en que, por el contrario, proponemos variantes de traducción.

2 Existen algunos antecedentes, pero pocos, en el Cuaderno Marrón y la Gramática Filosófica. Cf. al respecto Goldstein, 110-112.

3 Nos concentraremos en los pasajes relevantes de la segunda parte de las Investigaciones, los escritos tardíos sobre filosofía de la psicología y Zettel. El corpus asociado actualmente al «tercer Wittgenstein» incluye, además de dichos textos, Sobre la certeza y Observaciones sobre los colores.

Si cabe hablar o no de un «tercer Wittgenstein» es cuestión que, en el fondo, no parece tan decisiva. Las largas discusiones sobre "un Wittgenstein o dos» siempre han tenido un dejo de futilidad, siendo las continuidades tan innegables como los puntos de inflexión; e igual sospecha se aplicaría, claro, a la alternativa "dos o tres». Con todo, como Moyal-Sharrock y varios otros, pensamos que temas apenas apuntados en las Investigaciones y textos anteriores a 1946 reciben mayor énfasis y desarrollo en los escritos que nacen durante los cinco años posteriores. Lo parece confirmar también una referencia en la biografía de Ray Monk (quien se remite en este punto a G. H. von Wright): alrededor de 1947, y ocupándose del tema de los aspectos, Wittgenstein habría intentado seguir «una línea de pensamiento completamente nueva» (Monk, 549). 
al comienzo, en lo que Wittgenstein expresamente escribe sobre los temas en cuestión, permitiéndonos incluso a ratos un cierto detallismo textual; pero esbozaremos también, sobre todo hacia el final, un par de cuestiones respecto de las cuales los textos revisados no son más que sugerencias. Tales cuestiones giran en torno a la idea de un lenguaje propiamente humano en Wittgenstein.

Una serie de convicciones de largo alcance configuran el marco en el que se inscribe el presente texto. (a) La filosofía tardía de Wittgenstein, sobre todo la que se decanta en los escritos posteriores a las Investigaciones, exhibe una cierta concepción del ser humano. (b) Para elaborar los rasgos centrales de dicha concepción, se hace preciso integrar la interpretación de breves y escasas indicaciones textuales explícitas con la de pasajes, mucho más numerosos, en los que el tema de lo humano se halla en el trasfondo del tratamiento de otros temas. (c) Es posible articular la antropología filosófica atribuible al tercer Wittgenstein en torno a la idea de una segunda naturaleza: lenguajes y formas de vida llegan a configurar un sedimento cultural, tan connatural a cada ser humano como su equipamiento biológico ${ }^{4}$. (d) La vieja y correcta idea del lenguaje como constante antropológica adquiere en Wittgenstein una nota típicamente anti intelectualista, y esto en un doble sentido. En primer lugar, el autor pone énfasis en los modos de actuar irreflexivos («primitivos») que caracterizan nuestra vida lingüística: reacciones espontáneas, hábitos no cuestionados y, en general, comportamientos normativos «ciegos», es decir, carentes de justificación última (cf. Investigaciones filosóficas, \$219). Es precisamente por ese énfasis que la noción de segunda naturaleza resulta tan pertinente en este caso. $\mathrm{Y}$, en segundo lugar, Wittgenstein apunta a un aspecto afectivo o emocional que, como veremos, caracteriza la particular relación que los seres humanos mantenemos con una lengua en particular: la materna. (e) En su desarrollo intelectual, Wittgenstein se va acercando cada vez más a una concepción de la filosofía, de acuerdo a la cual la pregunta por el ser humano debiera ser constantemente el norte de toda actividad filosófica.

Todo lo que sigue apunta a hacer medianamente plausibles los puntos (a), (b) y el segundo aspecto mencionado en (d). El punto (c) quedará más bien implícito y en cuanto al punto (e), apenas pretendemos aquí motivar un tema, mostrando que existen buenas razones para al menos plantearse la pregunta por una evolución metafilosófica como la descrita.

Quisiéramos hacernos cargo, en este orden, de las siguientes tareas: exponer, distinguir y relacionar las nociones "vivencia del significado» (o también «vivencia de palabras») y «significado secundario» (2, 3 y 4); cuestionar una interpretación predominante, según la cual la llamada «ceguera para el significado» (Bedeutungsblindheit) se reduce a la incapacidad de percibir sutilezas del lenguaje poético (5), para sugerir que Wittgenstein apunta más bien a la idea de un lenguaje propiamente humano (6); referirnos brevemente a la relación entre significado secundario y metáfora (7); y, finalmente, mostrar qué puede querer decir todo lo anterior en relación al juego de lenguaje poético.

$4 \quad$ Ya Mulhall y, sobre todo, Medina han visto operando en el pensamiento de Wittgenstein el tópico aristotélico de una segunda naturaleza. 


\section{JUEGOS (EJERCICIOS) PARA VIVENCIAR PALABRAS}

Como explica Wittgenstein, al repetir muchas veces una palabra, ésta se vuelve mero sonido (Investigaciones filosóficas, II 491c); si hemos convenido con otra persona que «torre» significará para ambos lo mismo que habitualmente significa «banco» y si esa persona nos pide ir a la torre, la palabra nos sonará extraña; nos sonará extraña, aunque de hecho entendamos la petición, nos dirijamos al banco y encontremos ahí a nuestro interlocutor (II 491e); cuando reparamos en el nombre de algún famoso compositor o poeta, podemos tener la sensación de que el nombre mismo - «Beethoven», "Schubert», etc.- concuerda con su rostro y sus obras (II 493e, entre otros lugares); bien comprenderíamos lo que se nos pide, si alguien nos instara a pronunciar aisladamente la palabra "sino", primero como conjunción adversativa y luego como sustantivo (II 491c; Letzte Schriften, I 784) - de esa suerte de ejemplos se vale Wittgenstein para introducir los términos «vivencia del significado», "vivenciar el significado de una palabra» o también «vivencia de palabras»-.

Entre los casos referidos existen sin duda diferencias, y diferencias de diferente tipo, pero mucho más importante es aquello a lo cual todos apuntan: la idea de que las palabras de nuestros lenguajes naturales tienen su respectivo significado de alguna manera incorporado en su materialidad sonora o visual ${ }^{5}$. En efecto, más que de una idea, se trata de una experiencia: los ejemplos propuestos por Wittgenstein son ejercicios, en virtud de los cuales podemos recordar que nuestras palabras nunca son meros sonidos, que cada una tiene su fisiognomía propia y que su rostro es precisamente su significado (Investigaciones filosóficas, II 499m). A diferencia del modo en que más de un filósofo del lenguaje suele poner actualmente las cosas, no es que los sonidos devengan palabras. Es más bien al revés: vivimos desde un comienzo entre palabras y considerarlas sonidos obedece a una abstracción posterior, como lo demuestra la necesidad de repetir tediosamente un vocablo familiar para poder privarlo de su sentido. Cada palabra, pues, suena distinto teniendo el significado que tiene y es así como una misma palabra con dos significados («vela», por ejemplo) suena distinta en uno u otro caso: un mismo sonido nos puede sonar diferente. Ahora bien, resulta de suma importancia puntualizar que no experimentamos los significados inmersos en palabras mientras realizamos nuestros intercambios lingüísticos cotidianos (Observaciones sobre la filosofía de la psicología, I 202 y 232). Para tener vivencias de los significados se requiere de «ejercicios» como los ya señalados y que Wittgenstein llama «juegos» en más de una ocasión (Últimos escritos sobre Filosofía de la Psicología, I 59); un tipo absolutamente peculiar de juego de lenguaje, cabría acotar, puesto que en él no usamos nuestras palabras: las experimentamos o sentimos, pero no las usamos.

\footnotetext{
Se hallarán otros ejemplos en: Bemerkungen I 175, 182 y 242.
} 


\section{LA SILUETA DE LOS DÍAS}

La palabra «gordo» tiene, entonces, su fisiognomía propia. Ella misma es como gorda, ¿no? Pretender aplicarla a personas flacas nos parecería tan extraño (extraño, no imposible) como asociar el nombre de Nelson Mandela con el rostro de George Bush. Ahora bien, también nos podemos preguntar: ¿es el miércoles gordo? Al menos a Wittgenstein le parece más plausible - y otros nos sumamos- pensar que el miércoles sea gordo y el martes delgado que aplicar esta pareja de adjetivos a la inversa (Letzte Schriften, I 795). Estamos ante la segunda de las nociones wittgensteinianas que comentamos en el presente trabajo: en la oración «el miércoles es más bien gordo», la palabra «gordo» tiene un significado secundario o recibe un uso secundario, tal como sucede con la palabra «amarillo", si a alguien se le ocurre decir, como a Wittgenstein en Investigaciones Filosóficas (II 495h), que la vocal $e$ es amarilla ${ }^{6}$. Es fácil apreciar que en el primer ejemplo no se trata del significado o uso primario de "gordo", como lo confirma el hecho de que jamás le enseñaríamos esta palabra a un niño o extranjero que no la conociese refiriendo a un día de la semana. Y algo perfectamente análogo vale, claro, para el caso de la $e$ amarilla. No por ello, sin embargo, debiera identificarse el significado secundario — parasitario, por cierto, del primario- con el significado metafórico: «Si digo «la vocal $e$ para mí es amarilla no quiero decir: ‘amarilla con significado metafórico - pues lo que quiero decir no lo puedo expresar de otro modo que mediante el concepto <amarillo»" (Investigaciones Filosóficas, II 495h) ${ }^{7}$. Volveremos más adelante sobre esta distinción.

De cara a la relevancia filosófica del fenómeno, carece de mayor importancia si somos o no capaces de reconstruir la cadena causal de asociaciones - culturales, psicológicas, fonéticas o del tipo que sean- que podría develar el misterio de la silueta de tal o cual día. Personalmente, pensamos que el martes nos parece más delgado o magro que el miércoles, en buena parte porque el vocablo «miércoles» tiene simplemente más letras ${ }^{8}$. Pero podrían hacerse valer explicaciones muy distintas y hasta podría ser cierta una que sugiere el propio Wittgenstein: que una persona se incline a considerar el miércoles más bien gordo que delgado, porque durante su infancia un señor gordinflón le hacía clases todos los miércoles (Últimos escritos sobre Filosofía de la Psicología, I 795). Parece clara la intención de Wittgenstein: la hipótesis del profesor de los miércoles puede ser plausible, pero también podrían serlo muchas otras; el punto que realmente interesa (y que intentaremos mostrar en los apartados 5 y 6) no cambiaría un ápice de resultar cierta tal o cual hipótesis. En el tópico del significado secundario importa, pues, tener en cuenta que develar el misterio poco importa.

Tanto los ejemplos de vivencias de significados como los de significados secundarios presentan lo que se podría llamar «un cierto carácter intersubjetivo». Es lo que Wittgens-

Dicho sea de paso, el significado secundario representa uno de esos casos en que el significado no es el uso. Sobre este alcance del parágrafo 43 de las Investigaciones véase, entre otros, Garver (197-204).

7 Tampoco se trata de decir que el color amarillo corresponde a la «e; la gracia del juego (Witz des Spiels) está en decir que la ‘è es amarilla. Sobre ese ejemplo véase también la nota 16.

8 En alemán, en cambio, la explicación podría pasar fundamentalmente por la $n$ presente en Dienstag (martes) y que es un sonido que se asocia más a lo delgado (dünn: nótese de nuevo la n) que a lo gordo (dick); así las cosas, Mittwoch (miércoles) sería declarado gordo por descarte. En la otra versión del ejemplo, que trabaja con los términos "graso» (fett) y «magro» (mager) (Investigaciones Filosóficas, II 495d), la clave podría estar en la doble «t» presente tanto en Mittwoch (miércoles) como en fett (graso), de lo cual se seguiría ahora, nuevamente por descarte, el carácter magro del martes. 
tein, en nuestra opinión, quiere mantener en resguardo al no dejar de ocupar precisamente la palabra «significado» respecto de ambos tipos de fenómenos. Porque como quiera que se pretenda dar cuenta de esta palabra, el significado nunca responde a un capricho subjetivo, conlleva siempre intersubjetividad —una cierta intersubjetividad, cuando se trata de vivenciar palabras o usarlas secundariamente- ${ }^{9}$. Wittgenstein insiste, pues, en usar «significado» y en esa insistencia, como agudamente apunta Mulhall, «es la palabra 〈significado〉 [...] la que es tratada como si hubiese recogido en sí su significado» (258).

\section{DOS NOCIONES DISTINTAS, PERO RELACIONADAS}

Wittgenstein no distingue de un modo expreso las dos nociones que someramente hemos revisado, lo cual en parte explica que a veces se las tienda a confundir ${ }^{10}$. En cierto sentido resulta correcto afirmar que la noción «vivencia de significados de palabras» (cuya sustitución por «vivencia de palabras» no sólo abrevia las cosas, sino que conlleva de paso una sutileza filosófica, al neutralizar la tradicional tentación de hipostasiar significados) es más general que la de "significado secundario». Sin embargo, ello no debiera entenderse como si la relación entre ambas fuera del tipo género-especie, ya que los casos de significado secundario presentan características relevantes que en vano buscaríamos en la vivencia de palabras. La principal de ellas — cuestión poco subrayada en la literatura secundaria- es que mientras en dichos casos («gordo», por ejemplo, dicho del miércoles) las palabras no son usadas literalmente, en la vivencia de palabras no es sino su literalidad lo que nos interesa; y, por cierto, afirmar que no son usadas literalmente es del todo compatible con la afirmación de que tampoco se usan metafóricamente: el discurso metafórico es sólo una posibilidad entre otras de discurso no literal. Una segunda diferencia radica en que cuando hablamos de significados secundarios nos referimos a la aparición no literal de palabras en oraciones completas («la a es blanca»; «el martes es delgado»), mientras que los ejemplos de vivencias de palabras presentados por Wittgenstein, o su gran mayoría al menos, corresponden a lo que él mismo denomina por ahí: «vivencia del significado de una palabra aislada» (Últimos escritos sobre Filosofía de la Psicología, I 706; el énfasis es nuestro). Es más, este punto no es casual ni tampoco irrelevante, puesto que, como ya se indicó, no tenemos tales vivencias mientras usamos las palabras, es decir, mientras las usamos en oraciones.

No conviene, pues, entender la relación entre «vivencia de palabras» y «significado secundario» como la relación existente entre «mueble» y «silla». Con todo, es posible sostener, y en un doble sentido, que la vivencia de palabras representa un fenómeno más general que el de su uso secundario. Por un lado, porque si bien dicha vivencia se da únicamente al margen del empleo cotidiano del lenguaje, ella se halla siempre latente: con cualquier palabra podemos hacer en todo momento el ejercicio de imaginar lo extraña que suena aplicada inusualmente o el de repetirla aprisa experimentando cómo pierde su significado; no existe nada análogo a esa posibilidad siempre latente en el caso del uso secundario. Por otro lado, y quizá más importante, porque, pese a las importantes

\footnotetext{
9 Hablamos de una cierta intersubjetividad para hacer justicia al hecho de que haya personas con un bajo (aunque nunca nulo) grado de sensibilidad semántica.

10 Caemos en esta confusión en Fermandois.
} 
diferencias descritas en el último párrafo, es posible decir también que el uso secundario de palabras equivale, a fin de cuentas, a una forma muy específica, a la vez que intensa e inusitada, de vivenciar el lenguaje (lo que puede verse, pensamos, en Observaciones sobre la filosofía de la psicología, II 574).

Ahora bien, respecto de la relación entre ambos conceptos hay algo que nos parece más importante que todo lo anterior: que ambos apuntan en una misma dirección. Apuntan en una misma dirección, como podríamos decir que en cierto sentido lo hacen los términos «colegio»y «universidad». ¿En qué dirección apuntan?

\section{INSENSIBILIDAD SEMÁNTICA ${ }^{11}$}

Una manera de responder a la última cuestión es respondiendo primero a esta otra: "¿Qué le faltaría a quien no vivencia el significado de una palabra?» (Investigaciones Filosóficas, II 491b). A diferencia de lo planteado por diversos comentadores (Scholz; Zemach; Schulte), aquello que perdería alguien «ciego para el significado" (bedeutungsblind) no es, en nuestra opinión, cuestión menor y, en particular, no se reduce a la mera falta de sensibilidad poética o literaria ${ }^{12}$. Afirmar lo anterior no significa olvidar que el interés por la vivencia del significado jamás lleva a Wittgenstein a dudar de su crítica al modelo mentalista (subjetivista, privado, etc.) del significado, crítica que nuestro autor, fiel a su máxima de «la repetición como técnica», continúa urdiendo en los textos del tercer período. La discusión antimentalista se halla siempre presente, posee la máxima importancia y logra lo que se propone ${ }^{13}$. Pero permanecer en ella sería empobrecer el material que estudiamos.

Teniendo en cuenta que la ceguera para el significado (Bedeutungsblindheit) corresponde, en el terreno específicamente lingüístico, a la ceguera para los aspectos (Aspektblindheit), i.e., a la incapacidad general de ver algo como algo, hagamos un poco de exégesis textual. "¿Podría haber seres humanos — se pregunta Wittgenstein, sin revelar su parecer- a quienes les faltara la posibilidad de ver algo como algo [...]? [...] ¿Podría compararse este defecto con el daltonismo o con la carencia de oído absoluto?» (Investigaciones Filosóficas, II 489e). A la segunda pregunta cabe responder de forma negativa: mientras el daltónico ve colores cambiados, quien tiene dificultades con la famosa figura de Jastrow no la logra ver como pato o bien como conejo; y si carecer de oído absoluto significa no oír de inmediato la nota «la», ello se distingue estructuralmente de no poder oír un cierto pasaje musical como un lamento. Ahora bien, esa respuesta negativa a la segunda pregunta deja sugerida una no menos negativa a la primera, a saber, que la

11 Hemos tratado en Fermandois varios de los puntos que tocamos en este apartado y los dos siguientes. Sin embargo, a) el planteo es diferente, ya que aquel texto perseguía otro objetivo (describir aspectos visuales y emocionales de la comprensión metafórica), y b) el presente trabajo mejora y completa diversos aspectos de la exposición (véase, sin ir más lejos, la nota anterior).

12 Por el contrario, y en la línea de lo que también aquí se plantea, Gebauer se ha referido recientemente a una «familiaridad» y una «vínculación emocional» con nuestras palabras, sin confundir ni una ni otra con el especial talento de algunos en relación a la poesía y la literatura en general (215).

13 Como si estuviéramos aún en la primera parte del texto, encontramos en Investigaciones Filosóficas (II 497a) la tajante afirmación: «El querer decir [Meinen] algo es tan poco una vivencia como lo pueda ser el proponerse». 
posibilidad de seres humanos incapaces de ver algo como algo es más bien remota y que también la ceguera para los aspectos específicamente lingüísticos no puede ser sino un fenómeno muy ocasional. Esta sospecha es confirmada por textos no considerados por los intérpretes antes nombrados, en los que Wittgenstein se refiere a una persona ciega para los aspectos "como si tuviera, por así decir, un origen racial diferente» (Últimos escritos sobre Filosofía de la Psicología, I 56) o, más aún, como si correspondiera a «un tipo diferente de ser humano» (Últimos escritos sobre Filosofía de la Psicología, II 2). A esa consideración agreguemos un argumento: si la gran mayoría de las personas no fuera capaz de «saborear» $\mathrm{u}$ «oler» palabras en su significado habitual, formas de humor lingüístico probadamente exitosas y que sacan capital de entonaciones, acentuaciones, dicciones, etc., resultarían del todo inexplicables. Así lo plantea Wittgenstein en Últimos escritos sobre Filosofía de la Psicología (I 711).

Escribe Zemach: «La ceguera para el significado sólo es un obstáculo serio en un área [...]: arte» (493); y Scholz: «Vivencias del significado [...] son fenómenos marginales y secundarios» (232). Ninguna de esas afirmaciones hace justicia ni a los textos de Wittgenstein, ni a los fenómenos en cuestión. Es importante reconocer que sensibilidad semántica (de la que carecería un ciego para el significado) y sensibilidad poético-literaria no son lo mismo. Lo confirma, creemos, de un modo inequívoco el siguiente apunte de Wittgenstein: «Y si alguien fuera lo que denominamos «ciego para el significado», nos imaginamos que tendría que dar una impresión menos vital que nosotros, actuando más como un autómata» (Observaciones sobre la filosofía de la psicología, I 198).

\section{LENGUAJE HUMANO Y LENGUA MATERNA}

Los comentarios en torno a las últimas citas de Wittgenstein permiten señalar ahora aquello a lo que apuntan las dos nociones del autor, la enseñanza más general de su reflexión sobre las palabras y su fisiognomía ${ }^{14}$. Si hubiera que resumirla en una expresión, podría hablarse de una visión profundamente humana del lenguaje. En la primera parte de las Investigaciones, Wittgenstein destaca en repetidas ocasiones el rol de las reacciones prelingüísticas, el nivel de lo instintivo o "primitivo» que subyace a la comprensión lingüística. Esa enseñanza es complementada ahora por una nueva: la de que el dominio de técnicas lingüísticas no sólo nos pone en condiciones de llevar adelante nuestro cotidiano quehacer comunicativo, sino que viene a conformar de paso una segunda naturaleza que impregna de humanidad a la primera. Se trata ahora de reacciones, no menos espontáneas que la de mirar hacia la punta del dedo de un adulto, pero enfocadas esta vez al lenguaje mismo. El lenguaje se nos vuelve naturaleza, como lo sugieren las metáforas fisiognómicas de nuestro autor: «el rostro familiar de una palabra, la sensación de que ha recogido [aufgenommen] en sí su significado, de que es el retrato vivo de su significado» (Investigaciones Filosóficas, II 499m). Tenemos la impresión de que las palabras absorben su propio significado (aufsaugen) (Observaciones sobre la filosofía de la psicología, I 243) —y desde luego que es importante ocupar aquí el verbo «absorber» y no otro-.

14 La siguiente reflexión debe mucho a Mulhall, en particular en lo que toca a la noción de second nature (260). 
En un discreto paréntesis, Wittgenstein señala, ahora más literalmente, la cuestión fundamental respecto de seres humanos carentes de todo sentido fisiognómico: «(Les faltaría el apego [Anhänglichkeit] por sus palabras)»(Observaciones sobre la filosofía de la psicología, II 4991 ${ }^{15}$. La fisiognomía de la palabra alemana Anhänglichkeit es rica en resonancias: apego, por de pronto, pero también cariño, e incluso devoción, e incluso lealtad. Ahora bien, nada de ello se da primeramente en nuestra relación con el lenguaje en general, sino que sólo en aquella que mantenemos con una lengua muy específica, a saber, con nuestra lengua materna. La lengua materna es el hogar en el que se cría esa segunda naturaleza que todo ser humano adquiere qua ser parlante, y la ciudad natal en la que, un par de años después, se la encarna y despliega. Salvo los casos más bien excepcionales de completo bilingüismo, la relación con nuestra propia lengua nunca será igualada por la o las que podamos llegar a establecer con otras lenguas, de visita en otras ciudades (por lo demás, lo que distingue el caso de personas perfectamente bilingües no es que desaparezca la diferencia entre lengua materna y otras lenguas que se pueden aprender adicionalmente, sino que bajo la primera se subsuman varias). Por lo tanto, si hemos interpretado bien a Wittgenstein, los ciegos para el significado prácticamente no existen. $Y$ es que se trataría de sujetos carentes de una lengua materna, sujetos que no hablarían (al menos) una lengua como nativos. «Un tipo diferente de ser humano», por cierto.

Para ponerlo ahora en términos de relaciones internas: no tendríamos el concepto de un lenguaje humano si no tuviéramos el concepto de la lengua materna. Ambas ideas están ligadas internamente a través de las dos nociones de Wittgenstein que venimos de analizar. Una necesaria condición para que hablemos de lenguajes específicamente humanos es la existencia de aquellos fenómenos a los que tales nociones apuntan y que se dan del modo más nítido y acabado respecto de aquella lengua en que nos toca nacer y crecer.

\section{SIGNIFICADO SECUNDARIO Y METÁFORA}

En términos estrictos, el motivo que arguye Wittgenstein a fin de distinguir entre el caso de la $e$ amarilla y el de una metáfora en general resulta discutible ${ }^{16}$. Esto, porque existe un tipo de metáfora muerta, la catacresis, que tampoco permite expresar lo que se quiere decir sin usar precisamente la palabra en cuestión. La pata de la mesa no tiene otro nombre que el de "pata» y ocurre análogamente lo mismo con la cabeza del alfiler. Sin embargo, podemos convenir en que la catacresis representa un tipo muy singular de metáfora, en el que para dar nombre a cosas innombradas acudimos a una metáfora muerta (o la

15 Nos parece mejor traducir Anhänglichkeit por «apego» que por «cariño», como hacen García Suárez y Moulines. Es innegable que en la voz alemana resuena una connotación afectiva, pero ello también ocurre en «apego», que tiene, por su parte, la ventaja adicional de conservar la metaforicidad y ambigüedad del término alemán: hängen an: estar (a) pegado a.

16 El ejemplo de la $e$ amarilla es raro. Nuestra hipótesis es que funciona en alemán, pero no en castellano, y que la simple razón estriba en que gelb (amarillo) tiene precisamente una $e$ como única vocal. Acaso no sea un capricho personal que tendamos a asignar colores a las vocales del siguiente modo: la a nos parece blanca; la e, verde; la i, más o menos amarilla; la o, roja; y la u nos la podemos imaginar azul (o al menos la imaginamos mucho más fácilmente azul que en cualquiera de los otros colores). 
parimos muerta), evitando de paso una inflación léxica que podría resultar inmanejable. Podemos estar de acuerdo entonces en que, al margen del peculiar caso de la catacresis, la posibilidad de algún parafraseo — no hablamos, por cierto, de un parafraseo necesariamente exhaustivo- caracteriza el discurso metafórico.

Atractiva nos parece la propuesta que formula Hanfling para dar cuenta de la diferencia entre significado secundario y significado metafórico (127s.). Según él, la diferencia estribaría en que tratándose de metáforas es posible dar razones de lo que se dice y justificar así el inusual uso de un término, mientras que en el caso del significado secundario las razones parecen un imposible. Efectivamente, dar una interpretación o parafraseo no es otra cosa que ofrecer una explicación, mientras que cuando se dice que la «a» es blanca, las explicaciones, para decirlo con dejo wittgensteiniano, ya han llegado a su fin. Ese fin de las razones se observa también en la vivencia de palabras. Si nos preguntaran por qué la palabra «supermercado» le queda tan, pero tan bien a los supermercados, no sabríamos qué responder. Diríamos quizá «es simplemente así», lo que suena más a un rechazo de la pregunta que a su respuesta.

Pensando ya en el siguiente apartado, queremos extraer de la indicación de Hanfling la siguiente hipótesis: si es posible mostrar que existe una relación interesante del significado secundario - $-\mathrm{y}$, en general, la vivencia de significados- con la comprensión poética, lo dicho por él tendría la interesante consecuencia de que ese tipo de comprensión combina momentos racionales, relacionados con la interpretación o explicación de metáforas poéticas, y momentos ya no racionales, correspondientes a la captación de un significado secundario y, más en general, a la experiencia de las palabras. El antecedente de este largo condicional constituye el tema del siguiente apartado.

\section{¿Y LA POESÍA?}

Entre todo lo que cabe decir sobre la poesía como juego de lenguaje, algo que ciertamente no puede faltar es que en un poema las palabras se celebran a sí mismas (con la ayuda, claro, de un poeta). Roman Jakobson opone el lenguaje poético al lenguaje descriptivo (científico o cotidiano), planteando que mientras éste privilegia lo referencial - habla siempre de algo, de algo que le es externo-, aquél se orienta hacia adentro, hacia sí mismo — si habla de algo, el algo no es sino él mismo-. «La función poética [...] pone el énfasis en el lado palpable de los signos, subraya el mensaje por el mensaje [...]» (cit. en Ricoeur, 239, la traducción es nuestra). En la misma dirección apunta Mallarmé, al sentenciar, según se cuenta, que «los versos no se hacen con ideas, sino con palabras», al igual que Ricoeur, al describir el lenguaje poético como «un objeto cerrado sobre sí mismo» o como un tipo de lenguaje en el que «se mira al signo, más que mirar a través del signo» (278). Piénsese, por ejemplo, en el famoso «Poema 20» de Pablo Neruda: «Y el verso cae al alma como al pasto el rocío». Pregunta: ¿cuál verso es el que cae al alma? Posible respuesta: ese mismo. El verso que cae al alma como al pasto el rocío es: «el verso cae al alma como al pasto el rocío». Wittgenstein parece articular el concepto de comprensión que haría justicia a esa autorreferencialidad del lenguaje poético, cuando habla de una comprensión intransitiva de figuras reales (intransitives Verstehen). En tales casos, explica, no es que uno comprenda la figura así, introduciendo este «asíi la traducción, por decir de algún modo, 
de lo comprendido a una expresión diferente — como quien, al parafrasear, dice en otras palabras aquellas que comprendió (Philosophische Grammatik, 79)—. Quien comprende intransitivamente no está pensando en algo distinto, lo comprendido es entonces "cuasi autónomo» (Philosophische Grammatik, 79) ${ }^{17}$. Nuestro autor aplica la idea de la comprensión intransitiva al caso de la comprensión musical, pero pensamos que no habría tenido reparos en proyectarla también a la comprensión del lenguaje poético (si es que de hecho no lo hizo por ahí).

Ahora bien, veamos qué puede significar todo esto en relación con lo planteado en apartados anteriores. Recordemos, ante todo, que la vivencia de palabras no es algo que se pueda dar mientras las usamos en los juegos de lenguaje propios de nuestra comunicación cotidiana. Si bien la posibilidad de tener dicha vivencia se halla siempre latente, para activarla tenemos que dejar de operar con el lenguaje, como precisamente ocurre en los «ejercicios» o «juegos» de los que Wittgenstein se vale para introducir su noción de vivencia del significado. En un poema, en cambio, la posibilidad latente pasa a ser realidad constante. Dicho de otro y mejor modo, en la lectura de un poema se vivencia el significado de las palabras — su significado literal, secundario o metafórico- mientras las palabras están siendo usadas. No es necesario ahora dar un paso al lado de la práctica lingüística para recordar que cada una de nuestras queridas palabras tiene su rostro propio, pues en el caso de la poesía, la práctica lingüística consiste en mirarlas constantemente a la cara. Cuando se lee expresivamente una poesía, sostiene Wittgenstein, la palabra «está completamente llena de su significado» (Investigaciones Filosóficas, II 491g). Ahora bien, leer expresivamente una poesía constituye una práctica lingüística, en la que, por lo demás, las palabras tampoco aparecen aisladas. Ya no se trata, en definitiva, de meros ejercicios que se les han ocurrido a filósofos como Wittgenstein o James ${ }^{18}$. Se trata de reales usos insertos en nuestra forma de vida. Mientras en tales ejercicios experimentamos nuestras palabras en vez de usarlas, en la poesía las experimentamos precisamente al usarlas.

La poesía es entonces aquel juego de lenguaje que los seres humanos jugamos para activar o despertar algo que se halla siempre latente en el lenguaje en general: vivencias lingüísticas. Nos apuramos en aclarar que lo anterior no representa el intento - por lo demás, infructuoso en nuestra opinión- de ofrecer una definición de la poesía ni nada semejante. En particular, no creemos que la vivencia de palabras constituya un elemento suficiente de la experiencia poética y ni siquiera que sea un elemento estrictamente necesario, sino más bien típico.

Para concluir, una última reflexión: si no cabe concebir un lenguaje humano en el que las palabras carezcan de un rostro familiar para quienes lo hablan, es decir, en el que no se dé la posibilidad de vivenciar sus significados, pero si además la práctica poética no consiste, en buena parte al menos, sino en experimentar significados (mirar y admirar el rostro de palabras, oler sus aromas, escuchar su musicalidad), entonces cabría sospechar que un lenguaje propiamente humano sin poesía es algo más bien difícil de pensar. Si recordamos ahora la conexión esencial que existe entre la idea de un lenguaje humano y la idea de una lengua materna, el conocido hecho de que los seres humanos podamos dis-

17 En Johannessen se hallarán valiosas consideraciones al respecto.

18 Como ha observado Goldstein, el interés de Wittgenstein por el tema de la fisiognomía de las palabras parece nacer, o al menos estar relacionado, con su lectura de The Principles of Psychology de William James (114s). 
frutar de la poesía sólo o primariamente en nuestras respectivas lenguas maternas parece concordar perfectamente con dicha sospecha. En fin, la tesis de que sin la idea de poesía perderíamos también la idea de un lenguaje propiamente humano evidentemente no aparece, ni siquiera de un modo tácito, en los textos que han sido la materia prima de esta exposición. Estamos, sin embargo, convencidos de que dicha tesis se ajusta plenamente a lo que, recurriendo a una expresión cara al propio Wittgenstein, cabría denominar el «espíritu» de los escritos pertinentes de su tercer período.

Buena parte de lo que hemos planteado en el presente trabajo se podría resumir en un comentario a la siguiente cita, que combina lo explícito y lo implícito: «Si comparo con un sueño la presencia ante la mente del significado, entonces nuestro discurso habitualmente carece de sueños. El «ciego para el significado〉 sería, entonces, alguien que hablaría siempre prescindiendo de los sueños» (Observaciones sobre la filosofía de la psicología, I 232$)^{19}$.

En nuestra opinión, un aspecto clave de esa interesante analogía es el contrapunto entre los adverbios que aparecen en ambos párrafos: entre el «habitualmente» del primero y el «siempre» del segundo. No es ciertamente lo habitual que cuando usamos las palabras en nuestros juegos de lenguaje cotidianos experimentemos sus significados: las solemos usar, si se quiere, muy despiertos. Pero sería también muy extraño que alguien nunca sintiera o experimentara que las palabras llevan en sí mismas, como adosado a ellas, su respectivo significado. Forzando la analogía sólo un poco, aquello sería tan extraño como el hecho de que alguien nunca soñara o hubiese soñado. ¿Y el poeta? Bueno, cuando el poeta se vale de sus palabras pareciera hacerlo precisamente como soñando. Lo mismo que nosotros al leerlas y comprenderlas.

\section{REFERENCIAS}

Diamond, Cora. «Secondary Sense». The realistic spirit. Wittgenstein, Philosophy, and the Mind. Cambridge, Mass.: The MIT Press, 1991. 225-241. Medio impreso.

Day, William y Victor Krebs J. (Eds.). Seeing Wittgenstein Anew. Cambridge: Cambridge Universtity Press, 2010. Medio impreso.

Fermandois, Eduardo. "Imagen, aspecto y emoción. Apuntes para una fenomenología de la metáfora». Ideas y Valores. Revista Colombiana de Filosofía LVIII:140 (2009). 5-31. Medio impreso.

Garver, Newton. This Complicated Form of Life. Essays on Wittgenstein. Chicago and La Salle, Ill.: Open Court, 1994. Medio impreso.

Gebauer, Gunter. Wittgensteins anthropologisches Denken. München: Beck, 2009. Medio impreso.

Goldstein, Laurence. «What Does «Experiencing Meaning〉 Mean?». The Third Wittgenstein. The Post-Investigations Works. Ed. D. Moyal-Sharrock. Hampshire: Ashgate, 2004. 107-123. Medio impreso.

19 Luis Felipe Segura olvida traducir en el primer párrafo de este parágrafo la expresión adverbial «für gewöhnlich» (lo cual no empaña la calidad de su cuidada traducción de los dos volúmenes de las Observaciones sobre la filosofía de la psicología). Traducimos dicha expresión por «habitualmente». 
Hanfling, Oswald. «I heard a plaintive melody: (Philosophical Investigations, p. 209)». Wittgenstein Centenary Essays. Ed. A. Phillips Griffiths. Cambridge, Mass.: Cambridge University Press, 1991. 117-133. Medio impreso.

Johannessen, Kjell S. «Art, Philosophy, and Intransitive Understanding». Wittgenstein: Towards re-evaluation (Proceedings of the $14^{\text {th }}$ International Wittgenstein Symposium). Eds. Haller, R. y J. Brandl. Vienna: Hölder-Pichler-Tempsky, 1990. 323-333. Medio impreso.

Medina, José. «Wittgenstein's Social Naturalism: The Idea of Second Nature After the Philosophical Investigations». The Third Wittgenstein. The Post-Investigations Works. Ed. D. Moyal-Sharrock. Hampshire: Ashgate, 2004. 79-92. Medio impreso.

Monk, Ray. The Duty of a Genius. London: Vintage, 1991. Medio impreso.

Mulhall, Stephen. "Seeing Aspects». Wittgenstein: A Critical Reader. Ed. H. J Glock. Malden, Mass.; Oxford, UK: Blackwell, 2001. 246-267. Medio impreso.

Ricoeur, Paul. «The metaphorical Process as Cognition, Imagination, and Feeling». Philosophical Perspectives on Metaphor. Ed. M. Johnson. Minneapolis: University of Minnesota Press, 1981. 228-247. Medio impreso.

Scholz, Oliver. "Wie schlimm ist Bedeutungsblindheit? Zur Kernfrage von PU II, xi». Wittgenstein über die Seele. Eds. E. Von Savigny y O. Scholz. Frankfurt am Main: Suhrkamp, 1995. 213-232. Medio impreso.

Schulte, Joachim. Wittgenstein. Stuttgart: Reclam, 1989. Medio impreso.

Verdi, John. Fat Wednesday. Wittgenstein on Aspects. Philadelphia, PA: Paul Dry Books, 2010. Medio impreso.

Wittgenstein, Ludwig. Bemerkungen über die Philosophie der Psychologie. Werkausgabe, Band 7. Frankfurt am Main: Suhrkamp, 1984. Medio impreso.

-. Observaciones sobre la filosofía de la psicología. Segunda edición corregida. México, D. F.: UNAM, 1997. Medio impreso.

—. Investigaciones Filosóficas. Barcelona; México, D. F.: UNAM / Crítica, 1988. Medio impreso.

-. Letzte Schriften über die Philosophie der Psychologie (Band I). Werkausgabe, Band 7. Frankfurt am Main: Suhrkamp, 1984. Medio impreso.

-. Últimos escritos sobre Filosofía de la Psicología. Madrid: Tecnos, 1987. Medio impreso.

-.Philosophische Grammatik. Werkausgabe, Band 4. Frankfurt am Main: Suhrkamp, 1984. Medio impreso.

-.Zettel. Werkausgabe, Band 8. Frankfurt am Main: Suhrkamp, 1984. Medio impreso.

-.Zettel, México, D. F.: UNAM, 1997. Medio impreso.

Zemach, Hedí M. "Meaning, the Experience of Meaning and the Meaning-blind in Wittgenstein's Late Philosophy». The Monist 78:4 (1995). 480-495. Medio impreso.

Recepción: 7 de abril de 2011

Aceptación: 19 de mayo de 2011 